\title{
On the Value of Virtual Worlds for Collaborative Design
}

Panayiotis Koutsabasis, Spyros Vosinakis, Katerina Malisova, Nikos Paparounas

University of the Aegean,

Department of Product \& Systems Design Engineering

Konstantinoupoleos 2, 84100, Syros, Cyclades, Greece

Virtual Worlds have not been deployed widely in collaborative design, and their respective value is largely unknown. In this paper we make a combined use of established principles in design and computer-mediated communication studies to provide an account of their value for collaborative design by presenting three case studies concerned with: (a) review sessions of the architectural design of a cottage; (b) collaborative design of the interior space of an academic laboratory; (c) collaboration of design teams for the user interface design of a multimedia kiosk. We have found that collaborative design in VWs is a very engaging experience for remote participants and can add value to the activities of conceptual design and/or design review in the domains of design examined.

Keywords: Virtual worlds; computer- supported collaborative design; case study;

Virtual Worlds (VWs) are computer-generated, persistent 3D environments in which users co-exist as avatars exploring, building, interacting and communicating. The increase in processing power, graphics capabilities and network bandwidth of home computers have resulted to the emergence of a significant number of novel VW platforms and technologies during the last decade, like Second Life (SL) and World of Warcraft (WoW), drawing the attention of researchers from various disciplines. Maher (2011) presents VWs as the latest descendants of CVEs (Collaborative Virtual Environments) following (a) the first generation of CVEs (Benford et al, 2001) that were largely based on either Virtual Reality (VR) technologies or a mix of 2D and 3D user interfaces (e.g. VRML and the Web); and (b) Augmented Reality (AR) environments that offer virtual artifacts as replacements of tangible objects to the desktop computer screen. Indeed, VWs are the offspring of VR and networked 
desktop technologies, having left behind several shortcomings of VR - like the excessive cost of hardware interfaces, and allowing for social interaction in 3D spaces from the desktop computer.

It is not surprising that the design community is showing increasing interest in VWs for collaborative design. VWs have a number of affordances that are exploited to foster collaborative activities in various stages of design: communication, embodiment, presence and co-presence, 3D visualization and interaction, and increased user engagement as a result of all of the above. VWs have been employed to support some collaborative design activities including, among others: architecture and organizational or interior space design (Mobach, 2008; Vosinakis et al, 2008); virtual design studios (Bessière et al, 2009; Schmeil \& Eppler 2008); and collaborative learning in design education (D' Souza et al, 2011; Vosinakis et al, 2011).

Despite the increasing interest in exploring the affordances of VWs as a platform or 'tool' for mediating collaborative design activities, design studies in VWs are still scarce. This is reasonable not only because VWs are a new medium, but also because the design community would be interested in pragmatic uses of technologies that add value to existing practices. Therefore an investigation on the value of VWs for collaborative design activities has to examine the degree to which VWs affordances and tools can contribute to phases and activities of authentic collaborative design projects that involve designers' cooperation and client feedback.

In order to provide an account on the value of VW for collaborative design, we report on collaborative design studies in VWs combining: (a) a reflective (Schön, 1983) and social (Bucciarelli, 1988) perspective about designing with (b) practices in CMC (Computer-Mediated Communication) (Romiszowski \& Mason, 1996), CSCW (Computer-Supported Cooperative Work) (Schmidt and Bannon, 1992) and HCI (Human-Computer Interaction) evaluation and user experience (Sharp et al, 2007) studies. In particular, we present three case studies of collaborative design practice in VWs: (a) a design review session of the architectural design of a cottage focusing on the quality of communication among the designer and clients; (b) the collaborative design of the interior space of an academic laboratory with focus on situation awareness of collaborating designers; (c) the collaboration of three design teams for 
the user interface design of a multimedia kiosk. The experience out of these studies has shown that collaborative design in VWs is a very engaging experience for remote participants and can add value to the activities of conceptual design and/or design review in the domains of design examined; despite that a number of issues need to be further pursued in research and practice to allow for wider professional uptake of VWs.

\section{Affordances of Virtual Worlds for Collaborative Design}

The use of VR technology as a means for collaboration in various stages of design has been the focus of many research studies in the last couple of decades (Benford et al, 2001). Most of the initial approaches (e.g. Roussos et al, 1999; Normand et al, 1999) proposed the use of immersive hardware, such as CAVEs, HMDs, Data Gloves, etc. to take advantage of the realistic representations of the environment, the natural and intuitive interactions with the content, and the enhanced sense of presence that these environments have to offer. The key characteristics of these approaches, often termed as Collaborative Virtual Environments (CVEs), are the simultaneous existence of multiple users in the same virtual space represented as avatars, their communication, the shared exploration of $3 \mathrm{D}$ visualizations, and the collaborative construction of new content (Churchill and Snowdon, 1998).

CVEs have been proposed for various disciplines and phases, such as architectural design, product design, conceptual design, virtual assembly, etc. However, most of the relevant research work has focused on technical aspects, e.g. system architecture, fidelity and novel features, rather than on the applicability of these environments for professional use. Excluding the expensive and sophisticated VR solutions used in the industry for detailed construction and simulation (e.g. Dangelmaier, 2005; Cecil and Kanchanapiboon, 2007), it can be noted that the design community has not adopted CVEs for their everyday work. Some possible reasons for that may be the high cost of the immersive hardware, the limited availability of generic software platforms for immersive VR applications combined with the amount of time and money needed to develop customized solutions, and some serious usability issues related to the use of VR hardware, such as cybersickness (LaViola, 2000). 
The advances in computer hardware and gaming technology in the last decade have given rise to a new generation of collaborative VR applications running on desktop computers (Kan et al, 2001). These environments may not offer the immersive experience and the natural interaction of sophisticated VR solutions, but they have the significant advantage of being accessible to any user owning a computer or laptop with an average graphics performance. Desktop 3D graphics have been used for collaborative design in VR environments, with which visitors interact using standard keyboard and mouse interface, and in AR environments that are based on the interaction paradigm of tangible interfaces: users manipulate the $3 \mathrm{D}$ content by moving physical objects that act as patterns (Rekimoto, 1996). Both paradigms have their advantages and disadvantages; AR interfaces are more appropriate for colocated, face-to-face collaboration since all collaborators may concurrently manipulate the physical patterns; whilst VR interfaces allow for more generic interactions and application areas and are usually employed for remote collaborations. Although Desktop 3D technology has surpassed the problems of high cost and cybersickness mentioned before, the issue of software complexity and lack of standards remains. Virtual Worlds (VW) may, however, be seen as an attractive alternative.

The term Virtual Worlds (VWs) is nowadays being used to refer to Desktop MultiUser Persistent 3D Environments (Bartle, 2003). A large number of VWs are currently available on the Internet, some of which are game environments, e.g. the popular WoW, and others are generic purpose environments for communication, exploration and creative expression. Currently the most popular generic-purpose environment is Second Life (SL), which has a user base of around 20 million users. The important feature of some VWs, including SL, is that they offer their own scripting language to be used for extending the world's functionality and defining specific object behavior. This makes them customizable and allows developers to design and implement application-specific tools whilst taking advantage of the existing visualization, interaction and communication infrastructure of the VW. Therefore, compared to typical application-specific VR and AR applications that have to be built from scratch, VWs can be used as a powerful platform for designing novel collaborative design environments (Merrick et al, 2011) 
VWs have a number of characteristics that may be beneficial for designers in various stages of their work:

First of all, they are $3 D$ visualization platforms, and as such they allow the understanding of the form and structure of real or hypothetical objects and places. 3D models do not necessarily have to be realistic; they may be used as metaphors to present more abstract concepts. Therefore, the use of 3D graphics may be useful in several design process from communicating ideas and concepts to more detailed presentations of artifacts. A number of VWs are using advanced rendering algorithms and may produce high quality visualizations in real-time, thus allowing a designed artifact to be evaluated.

Furthermore, VWs can be used as simulation environments. Being real-time systems, they certainly have much lower fidelity and accuracy compared to professional CAE (Computer-Aided Engineering) applications, but they can still be used to visualize processes, operations and activities in real time. Again, this feature may be valuable for evaluating prototypes even in low fidelity. And, given that VWs are inherently interactive, users may interact with the simulated artifacts, and experience a simplified form of virtual testing.

The real-time navigation of users offered in VWs using various interaction techniques, metaphors and aids can be valuable for exploring and evaluating designed places from first or third person view. This ability can be used for architectural walkthrough of interior or exterior spaces and for generic overviews or detailed observations of designed concepts.

Furthermore, the ability to add, delete and manipulate objects in real-time allows multiple users to co-construct a solution in a synchronous manner and to be instantly aware of each other's actions. This is invaluable for the collaborative design of concepts or proposing ideas and alterations in the form or structure of a designed solution in a discursive manner.

In most studies of collaboration in VWs, it is reported that users feel a sense of presence, or psychological immersion, while interacting with VWs. This makes them feel as being in-the-world, rather than being external observers of a 3D model, as in 
using CAD environments. Therefore, users of a well-designed VW may imagine themselves being located in the designed place and using the designed service or product, and thus they can have an initial evaluation of the concept, e.g. to detect some critical ergonomic or usability issues that they had not thought of whilst designing the form and structure of the prototype.

Another unique characteristic of VWs is the user embodiment. Users are not just viewers of the virtual space, they exist in it as avatars, and their motion and actions are observable by others in real time. This feature allows for several forms of nonverbal communication and user awareness. The avatars' position and orientation communicate where they are and what are they looking at; their appearance can be usually modified to express the user's personality, or even to denote the role of the user in a collaborating team; their animated bodies communicate their current activity; in some VWs the avatars may also use facial expressions and gestures as an additional means of communication. All these abilities are important for the quality of the remote communication and coordination of a design team. Furthermore, the use of anthropomorphic avatars for evaluating the design of a place or the usability of a designed product may help reveal issues related to ergonomics. Users are not just browsing a place or an object, but they actually experience their avatar (in first or third person view) walking in the place or holding the object, so they can have a deeper understanding of the functionality of the concept, prototype or service.

Finally, VWs offer various forms of synchronous and asynchronous communication. Users may communicate in real-time using voice or text chat, and they may also send offline messages to single or multiple users. Obviously, these features are essential requirements for collaborative design. Furthermore, VW users may post annotations in the environment, i.e. messages linked to specific objects or places. Annotations may be used in several stages of design, e.g. as requirements, reviews of proposed concepts, proposals for restructuring, etc., and the fact that they can be attributed to existing objects in the environment makes the communication even richer.

Most of the characteristics mentioned above are not unique of VWs; they can be found in other platforms or applications, sometimes at a much higher quality, e.g. video conferencing for real-time communication, e-mail for offline messaging, 3D 
modeling programs for product design and CAD environments for simulation. However, there is a clearly added value in VWs on the integration of all of the above characteristics. In a $\mathrm{VW}$, users communicate in real time while being in the designed space, being able to point to specific attributes, objects or places, being able to instantly communicate an idea, restructure a solution, evaluate a concept. It all happens in the same space, and therefore there is greater awareness and coordination of the collaborating design team.

Another added value is the accessibility and usability of VWs compared to professional CAD applications. They do not have high hardware requirements and they are not designed for professionals; their user interface is much simpler. Thus, non-professionals can be much more easily involved in the design process. Potential clients may review the proposed concepts, may express their concerns or counterpropose alterations. This aspect of VWs has been already explored by some companies, as they are using Second Life to let customers review products under design before they are being sent to production (Kohler et al, 2008) and storefronts (Bassiere et al, 2009) and to communicate innovation (Maisch and Tobies, 2010).

\section{Related studies and rationale of the research}

There are many studies of collaborative design in VEs (Virtual Environments), where the term denotes nearly any type of networked technology, including: VR, AR, the Web, Web-enabled VWs, and VWs. These studies present a wide diversity of general framings and specific issues about the quality of collaborative design mediated by VEs.

A considerable number of studies investigate the understanding of design tasks in VEs from a cognitive perspective that emphasises participants' actions and behaviours. These studies usually compare designers' behaviour in different collaborative design situations or VE technologies. For example, in Gul \& Maher (2008) the co-located design situation is compared to the VE-mediated situation; in Kim \& Maher (2008) the collaborative design with $\mathrm{AR}$ is compared with that of using typical to $3 \mathrm{D}$ modelling tools; in Kan et al (2011) the situation of 'small-scale' design is compared to that of 'large-scale' design in a VW. 
More specifically, Gul \& Maher (2008) have conducted a series of experiments to identify similarities and differences between co-located and remote design sessions to gain an understanding of the impact of different virtual environments on design collaboration. They report on pairs of designers collaborating on design tasks "of similar complexity" using a different design environment for each task: face to face sketching, remote sketching, and 3D virtual world; and they conclude that the behaviour patterns and design actions and the characteristics of design process are quite different in sketching compared to the 3D world environment. Also, Kim \& Maher (2008) present a comparative design protocol analysis of collaborative design sessions between a tangible user interface (TUI) with a typical keyboard/mouse/display graphical user interface (GUI) focusing the identification of changes in designers' spatial cognition. The results reveal that the use of TUIs changed designers' spatial cognition, and that these changes affected the design process by increasing their 'problem-finding' behaviours leading to creative design. Finally, Kan et al (2011) investigate the impacts of large and small scales of designed objects reflecting on two protocol-based experiments of large-scale vs. small-scale collaborative design in VWs, and they suggest guidelines for further improvements regarding scaling, gestures and presence.

These studies determine a-priori the lenses from which they will observe design behaviour and they analytically record designers' actions with protocol analysis, e.g. according to Kan et al (2011) "before analysing the protocols, it is important to know what cognitive processes are to be studied because it is impossible to model the entire cognitive processes". The approach is experimental and the setting is controlled allowing the researcher to observe the specific design collaboration task (e.g. cosketching, co-construction, communication, etc.) mediated by the VE. In general, protocol studies are important in domains of design where the goal is to understand design thinking by observing and interpreting expert design behaviour and in cases of atomic design work; however they suffer from important limitations that stem out of the experimental setting that inevitably leaves out issues that would arise in real or authentic contexts. For example, Cross (1995) notes that "the experimental set-up heavily influences the protocol data, and the amount of interpretation needed to wrench conclusions from the protocol data is also comparatively large". 
A number of studies have looked at the pragmatic use of VEs for collaborative design, beyond the experimental setup; in these studies the design collaboration is carried out in authentic or real projects.

Dretakis et al (2007) present the design of a realistic VR environment for architectural and urban design of open spaces of the city of Nice in terms of a real project that involved the construction of a Tramway. This involved $8 \mathrm{~km}$ of rail in the most dense parts of the city, requiring the re-design of several open spaces such as the main city squares. Dretakis et al present a user-centered design approach to the development of this Virtual Environment (VE) that involved project stakeholders and end-users i.e., architects, chief engineers and decision makers and their evaluation results suggest that the VR environment enables a better appreciation of space and physical objects as well as the sense of scale for users.

Lahti et al (2004) examined the intensity of design collaboration in a course of textile teaching, and specifically for the authentic task involving clothing for premature babies, which was mediated by a Web-based collaborative learning environment. The study employed qualitative content analysis of students' written notes and sketches posted to the database and resulted to a number of encouraging findings about students' engagement to computer-mediated collaborative design.

In addition to these, Mobach (2008) presents two case studies of the use of a VW for assessing architectural and organizational space design. The case studies included the immersion of project stakeholders into the virtual prototype of the architectural space of a pharmacy building in the context of the wider activity of participatory design meetings. The results show that the design was changed, staff satisfaction was improved and costs were reduced. This work has shown that VWs can contribute to the creation of better real worlds in the domain of organizational space design.

These studies report on aspects of the value of VEs in authentic or pragmatic situations and show real uses of VEs for supporting various aspects of design collaboration. However, with the exception of the work of Mobach (2008) they do not refer to 3D VWs. Thus, although there seems to be potential in VWs as a future platform for collaborating design teams, the use of VWs in collaborative design 
activities is still in its infancy. The distinction between the specific technology of VWs and VEs in general is important. According to Maher (2009) "a specific collaborative design environment makes a commitment to the way in which the designers can communicate and co-create". More generally, if we consider collaborative design as a complex activity (Engeström, 1991) mediated by the VW, then we will have to admit that the characteristics of the tool that mediates the objective of the activity affect the formulation of our understanding about the activity itself. Thus, a first distinguishing point of our research is that we are investigating VW platforms that have unique user interaction affordances (discussed in section 1) and overcome many of the obstacles identified in past VEs.

Furthermore, in collaborative design situations many people are involved with ranging backgrounds and expertise, while the design activity is inherently complex with goals that are gradually formulated and understood from different perspectives during the project lifetime. In addition, it is often that collaborative design projects have intangible outcomes (e.g. services, processes, software) that are hard to evaluate while the success criteria depend much on customer interaction and experience. In such a framing, it is useful to consider the collaborative design activity as the unit of analysis, in contrast to the experimental approach that emphasises the study and interpretation of user actions; according to Bannon (1991) actions cannot be isolated from the complex context in which the occur. Each action has to be interpreted and situated within a purposeful collaborative design activity, which is mediated by VE tools and it evolves in an authentic or pragmatic context of design practice.

Thus, to provide an account about the value of VWs in collaborative design, we first specify the particular affordances of VWs and then we follow a research approach based on case study research that can bring us closer to real or authentic projects and contexts of design practice. Case study research is valuable for practitioners because it can provide insights for design and evaluation based on pragmatic situations and experiences, provided that the context of the study (setting, goals, participants, method) is clearly presented, and the goals of the study are interesting and important for the community. Thus, in our design and evaluation work in VWs, we are interested in (a) setting up pragmatic (or at least authentic) collaborative design 
situations that extend the experimental settings of many other studies; (b) designing particular tools in VWs that effectively mediate collaborative design situations and (c) assessing the quality of collaborative design activities with emphasis on practical issues and the user experience.

\section{Case studies of Collaborative design in VWs}

\subsection{Study Design}

\subsubsection{The VW platform}

The VW implementation has been based entirely on open source software. The world server was installed in a standalone PC using the OpenSimulator platform ${ }^{1}$, and the FreeSwitch server ${ }^{2}$ has been set up and connected to the environment to provide voice communication support. We have created small islands and built a number of interior and exterior places for group collaborations. In addition for each case study we implemented a number of additional collaboration tools in the LSL Scripting language. On the client side, the Hippo OpenSim Viewer ${ }^{3}$ was running on PCs with standard keyboard and mouse equipment plus an additional headset with microphone for voice communication. The main reasons for setting up our world in the OpenSimulator (OS) platform instead of the more popular world of SL were:

1. Visualization and functionality: there are no differences in graphics quality (both platforms use the same client) and OS supports most of the functionality of SL.

2. Cost: Besides the cost for owing private land, SL places a charge for every image uploaded. In our studies the participants had to upload a lot of images to construct prototypes. A limitless number of images can be uploaded in OS at no cost.

3. Data Recording: Using OS we managed to record all voice sessions directly from the server. This would not be possible in SL - we would be able to record only public discussions in close range.

\subsubsection{Principles for Study Design}

\footnotetext{
${ }^{1} \mathrm{http}: / / \mathrm{www} .0$ pensimulator.org

2 http://www.freeswitch.org

3 http://mjm-labs.com/viewer
} 
We have conducted a number of studies of collaborative design in VWs that span across a number of design activities allowing us to draw some conclusions on the value of VWs for different design situations. We have identified a set of unifying principles for study design based on practices of analysing design activity in general (Cross et al, 1997) and collaborative design activity in particular (Valkenburg and Dorst, 1998; Cheng, 2003), that emerge from a reflective (Schön, 1983) and social (Bucciarelli, 1988) perspective about designing. In addition, we take into account related practices in CMC (Romiszowski \& Mason, 1996), CSCW (Schmidt and Bannon, 1992) and HCI evaluation and user experience (Sharp et al, 2007) studies. The principles for study design concern the following aspects of design studies in VWs:

I. Problem, process and outcome of design collaboration

A. Ill-defined or 'wicked' problem at hand: According to Cross \& Cross (1995) "in design, it is not normal to have a clear and immediately apparent problem given as the task, in the way that is normal in other problem solving studies". Indeed, in practice the goal(s) of design are rarely well-defined - on the contrary, it is often that designers are presented with just a few statements of a problem definition and it is their task to seek to understand the problems before providing solutions.

B. Design process reflection ('reflection-in-action') and negotiation (among design participants). In practice, the design process is fluid and determined upon the design participants' knowledge and experience. According to Schön (1983) designers continuously reflect on their strategies and actions ('make moves') to change the design situation. Additionally, from a social perspective, each stakeholder of a design project sees design differently - according to Bucciarelli (1988): "Scholar, manager, engineer or artist, each with different interests and motive, sees designing in a different way. Ranges of view, depths of field and primary foci differ." Therefore, in collaborative design studies it is important to make sure that participants freely select and negotiate processes and strategies. 
C. Concrete outcome: designing must result to one (or more) concrete outcome(s) that can be evaluated and discussed by design participants.

\section{Participants}

A. Pragmatic (or at least authentic) project and participants: design studies typically concern pragmatic design projects that involve professional designers and stakeholders, placing a focus on empirical results. In CMC studies, when learning and technology research objectives are pursued, authentic projects are also acceptable. For CMC design studies, that would be a project involving less experienced designers (typically students) and possibly representative clients or users for user experience and usability studies (Tullis \& Albert, 2008). Authentic projects are still drawn from practice in some form of scenarios (Carroll, 1995).

B. Genuine contribution: it is critical that all participants are motivated to contribute with their best efforts in any design study. Incentives for genuine user involvement (Grudin, 1991) include several types of rewards and acknowledgements, while in more controlled HCI evaluation studies ethical issues must also to be taken into account (Blanford et al, 2008).

III. VW tools and affordances.

A. Familiar VW tools and metaphors from design practice. Collaborative design activities in a VW are mediated by digital tools (Fjeld et al, 2002). VWs come with a set of general-purpose tools that allow interaction with the 3D content, communication, navigation and so on. In addition, particular design activities have to be supported by tools that serve specific purposes on the basis of relevant metaphors (Blackwell, 2006) from design practice.

B. Exploitation of 3D VW affordances for digital tool design. The conduction of collaborative design activities in VWs requires organization of digital places (Harrison \& Dourish, 1996) for collaboration and digital tools for design communication, representation, modeling and documentation. The design space for introducing digital tools for supporting collaborative design 
activities in VWs is practically unlimited. It is important for VW designers to exploit the 3D affordances of VW (see related work section above) rather than simply transfer 2D tools into the 3D space.

C. Design VW tools that mediate design activities at various levels of abstraction. Most approaches for the design and development of VWs for collaborative design deploy tools that remain at the level of supporting instrumental and communicative activities. However, from a social action perspective (Vosinakis et al, 2008) design can also be discursive in the sense that design goals and actions are negotiated or strategic in the sense that it is oriented towards influencing and transforming the behaviour of other participants or the group, therefore the design of VW tools can address these type of activities as well.

IV. Data collection and assessment

A. Types of assessments. Collaborative design studies in VWs may report on various impacts on design activity, such as: (a) quality and acceptance of the outcome; (b) participants' use of processes, tools and methods; (c) aspects of design collaboration (e.g. awareness, communication, etc.); (d) user experience.

B. Mixed use of behavioural and self-reporting data. In VWs it is possible to collect various types of data about user behaviour in the digital space, especially by making use of (video, audio, chat) recordings and automated logs. These have to be matched with self-reporting and self-reflection that will explain participants' actions. The need for capturing and analyzing own design activity is discussed in design studies (Pegley, 2007). Collaborative design studies in VWs require a mixed, largely qualitative approaches for data collection and analysis that rest on human interpretation, therefore the cross examination (or triangulation (Strauss \& Corbin, 1990)) of data from respective methods is required.

These principles have been developed to better explicate our approach for the collaborative design studies in VWs since that these are essentially transdisciplinary, 
lying at the intersection of the fields of design, collaboration, HCI and VWs. Error!

Reference source not found. outlines the specific characteristics of the case studies that follow, with respect to the principles outlined.

Table 1: specific characteristics of the case studies with respect to outlined principles.

\begin{tabular}{|c|c|c|c|}
\hline & $\begin{array}{l}\text { Case Study \#1: } \\
\text { Designer-client review } \\
\text { sessions of } \\
\text { architectural design } \\
\text { focusing on the quality } \\
\text { of communication }\end{array}$ & $\begin{array}{l}\text { Case Study \#2: Design } \\
\text { team collaborations for } \\
\text { the interior space design } \\
\text { of an academic } \\
\text { laboratory with focus on } \\
\text { situation awareness }\end{array}$ & $\begin{array}{l}\text { Case Study \#3: Design team } \\
\text { collaborations for user interface } \\
\text { design of a multimedia kiosk } \\
\text { with focus on problem-based } \\
\text { collaborative learning. }\end{array}$ \\
\hline \multicolumn{4}{|c|}{ 1. Problem, process and outcome of design collaboration } \\
\hline $\begin{array}{l}\text { I.A. Ill-defined or } \\
\text { 'wicked' problem } \\
\text { at hand }\end{array}$ & $\begin{array}{l}\text { Architectural design } \\
\text { review of a cottage by } \\
\text { the sea }\end{array}$ & $\begin{array}{l}\text { Interior space and service } \\
\text { design of an academic } \\
\text { laboratory }\end{array}$ & $\begin{array}{l}\text { Design of the user interface of a } \\
\text { multimedia kiosk for tourist } \\
\text { information }\end{array}$ \\
\hline $\begin{array}{l}\text { I.B. Design process } \\
\text { reflection and } \\
\text { negotiation }\end{array}$ & $\begin{array}{l}\text { Yes (the process was } \\
\text { formulated on the basis } \\
\text { of experience) }\end{array}$ & $\begin{array}{l}\text { Yes (the process was } \\
\text { formulated on the basis of } \\
\text { experience) }\end{array}$ & $\begin{array}{l}\text { Yes (the process was formulated } \\
\text { on the basis of experience) }\end{array}$ \\
\hline $\begin{array}{l}\text { I.C. Concrete } \\
\text { outcome }\end{array}$ & $\begin{array}{l}\text { The conceptual design } \\
\text { of the cottage }\end{array}$ & $\begin{array}{l}\text { The conceptual design of } \\
\text { the academic lab }\end{array}$ & $\begin{array}{l}\text { The conceptual design of } \\
\text { alternative user interfaces }\end{array}$ \\
\hline \multicolumn{4}{|c|}{ 2. Participants } \\
\hline $\begin{array}{l}\text { II.A. Pragmatic (or } \\
\text { authentic) project } \\
\text { and participants }\end{array}$ & $\begin{array}{l}\text { Real: } 1 \text { professional } \\
\text { designer; } 4 \text { clients }\end{array}$ & $\begin{array}{l}\text { Real/authentic: } 1 \text { team of } \\
3 \text { professionals; } 1 \text { team of } \\
\text { graduate design students }\end{array}$ & $\begin{array}{l}\text { Authentic: } 3 \text { teams of graduate } \\
\text { design students ( } 10 \text { students } \\
\text { overall); } 2 \text { instructors } \\
\text { (professionals in HCI evaluation) }\end{array}$ \\
\hline $\begin{array}{l}\text { II.B. Genuine } \\
\text { contribution }\end{array}$ & $\begin{array}{l}\text { Yes (pragmatic } \\
\text { situation) }\end{array}$ & Yes (pragmatic situation) & $\begin{array}{l}\text { Yes (learning situation, with } \\
\text { incentives for participation) }\end{array}$ \\
\hline \multicolumn{4}{|c|}{ 3. VW tools and affordances } \\
\hline $\begin{array}{l}\text { III.A Familiar tools } \\
\text { and metaphors from } \\
\text { design practice }\end{array}$ & $\begin{array}{l}\text { (a) annotation; (b) area } \\
\text { marker; (c) } \\
\text { collaborative board; (d) } \\
\text { note-board }\end{array}$ & $\begin{array}{l}\text { (a) collaborative sketch } \\
\text { tool (b) interactive } \\
\text { whiteboard }\end{array}$ & $\begin{array}{l}\text { (a) resource; (b) comment } \\
\text { recorder; (c) annotation; (d) } \\
\text { InterfaceElement }\end{array}$ \\
\hline $\begin{array}{l}\text { III.B. Exploitation } \\
\text { of VW affordances } \\
\text { for tool design }\end{array}$ & Yes & Yes & Yes \\
\hline $\begin{array}{l}\text { III.C. Design tools } \\
\text { that mediate design } \\
\text { activities at various } \\
\text { levels of abstraction }\end{array}$ & $\begin{array}{l}\text { The collaborative board } \\
\text { allows for discursive } \\
\text { design activities. The } \\
\text { rest for communicative } \\
\text { activities }\end{array}$ & $\begin{array}{l}\text { Both tools allow for } \\
\text { discursive design } \\
\text { activities }\end{array}$ & $\begin{array}{l}\text { All tools cater for instrumental } \\
\text { (user interface design) and } \\
\text { communicative activities }\end{array}$ \\
\hline \multicolumn{4}{|c|}{ 4. Data collection and assessment } \\
\hline $\begin{array}{l}\text { IV.A. Types of } \\
\text { assessments }\end{array}$ & $\begin{array}{l}\text { (a) outcome; (b) use of } \\
\text { tools; (c) quality of } \\
\text { communication; (d) } \\
\text { user experience }\end{array}$ & $\begin{array}{l}\text { (a) outcome; (b) quality of } \\
\text { built-in VW awareness } \\
\text { mechanisms; (c) user } \\
\text { experience }\end{array}$ & $\begin{array}{l}\text { (a) outcome; (b) use of tools; (c) } \\
\text { learning; (d) collaborative design } \\
\text { experience }\end{array}$ \\
\hline $\begin{array}{l}\text { IV.B. Mixed use of } \\
\text { behavioural and } \\
\text { self-reporting data }\end{array}$ & $\begin{array}{l}\text { Yes, data out of: (a) } \\
\text { observation, (b) } \\
\text { questionnaires; (c) } \\
\text { dialogue analysis }\end{array}$ & $\begin{array}{l}\text { Yes, data out of: (a) } \\
\text { observation, } \\
\text { (b)questionnaires; (c) } \\
\text { interviews }\end{array}$ & $\begin{array}{l}\text { Yes, data out of: (a) automated } \\
\text { monitoring of student behaviour } \\
\text { (video; logfiles; text; voice); (b) } \\
\text { dialogue analysis; (c) self- } \\
\text { reporting; (d) tutors' evaluation of } \\
\text { learning and outcome. }\end{array}$ \\
\hline
\end{tabular}




\subsection{Case study 1: Designer-client review sessions of architectural design focusing on the quality of communication}

\subsubsection{Goal, Focus, Participants and Process}

The goal of the first VW design study was the architectural design review of a cottage by the sea. The study focused on the assessment of the quality of communication in design collaboration in VWs. In particular, the term communication is used in this respect to describe the exchange of information between users as well as information provided by the system to them. The study examined the extent to which VW communication tools allow for a comprehensive and efficient way to transmit and understand information. The participants were:

- One (1) member of the research team, who is a professional architect and the chief architect of the cottage. In all, three (3) professional architects designed the cottage (outside the world); however the chief architect built the cottage (in the world - the other architects approved the design before it was presented to the clients) and participated in the design review activity (in the world).

- Two (2) groups (couples of male and female) were the potential clients for the cottage. They were real clients in the sense that they were indeed interested for the cottage and they were also willing to try the experience of the VW. Each couple carried out the design review process independently.

With respect to the tools, the VW offers some built-in tools and affordances for communication and information exchange like: text chat, avatar gestures, voice chat, colour palette, texture library, mini-map (for location awareness), and pointing. We created four additional tools that fit better to the specific design activity: (a) the annotation tool for posting comments and requests in specific objects or places; (b) the area marker for marking large areas; (c) the message board for posting messages; and (d) the note-board for exchanging small notes. 


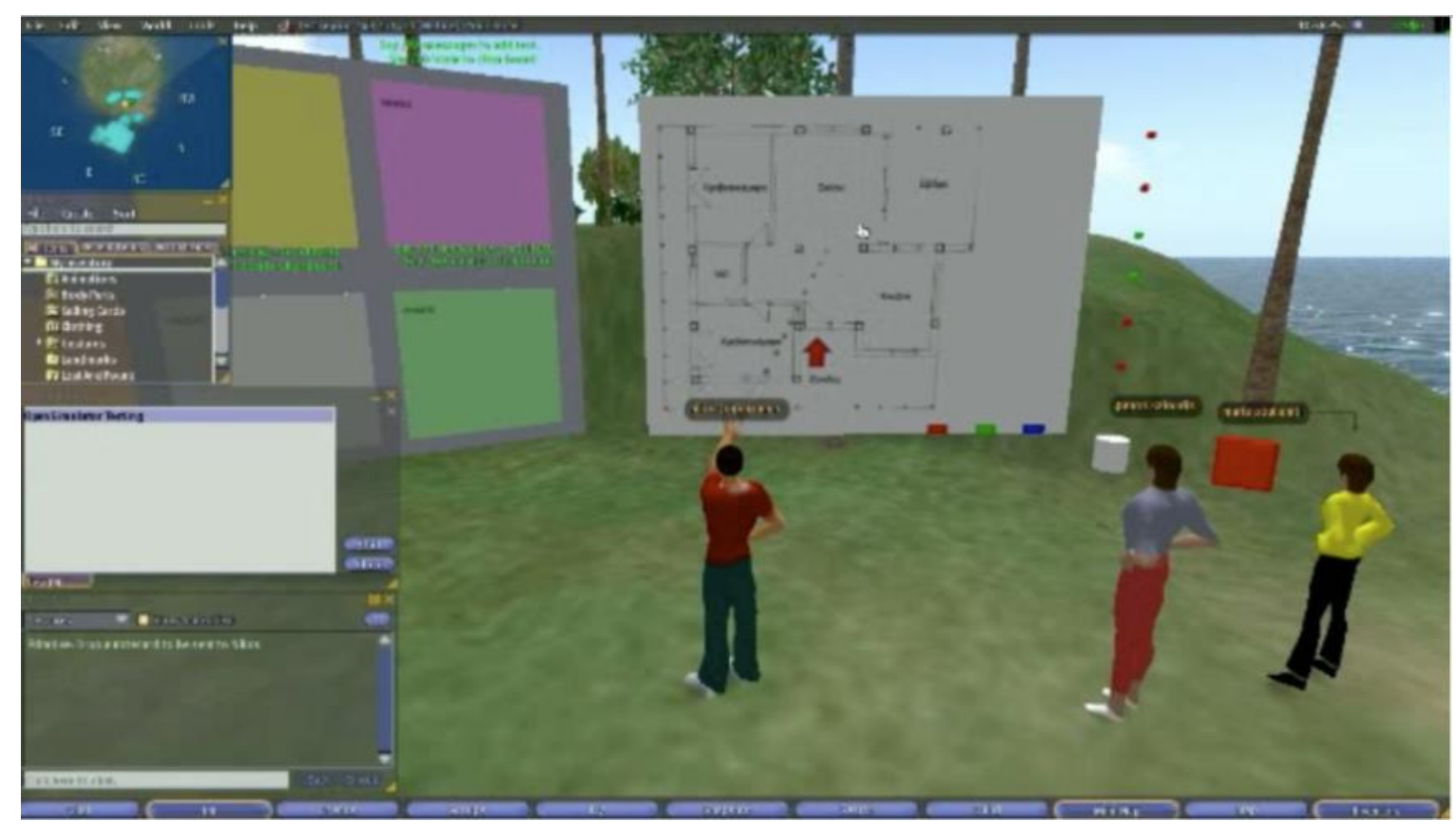

Figure 1: The chief architect and the client couple communicate during the design review process using the note tool, the area marker and text chat.

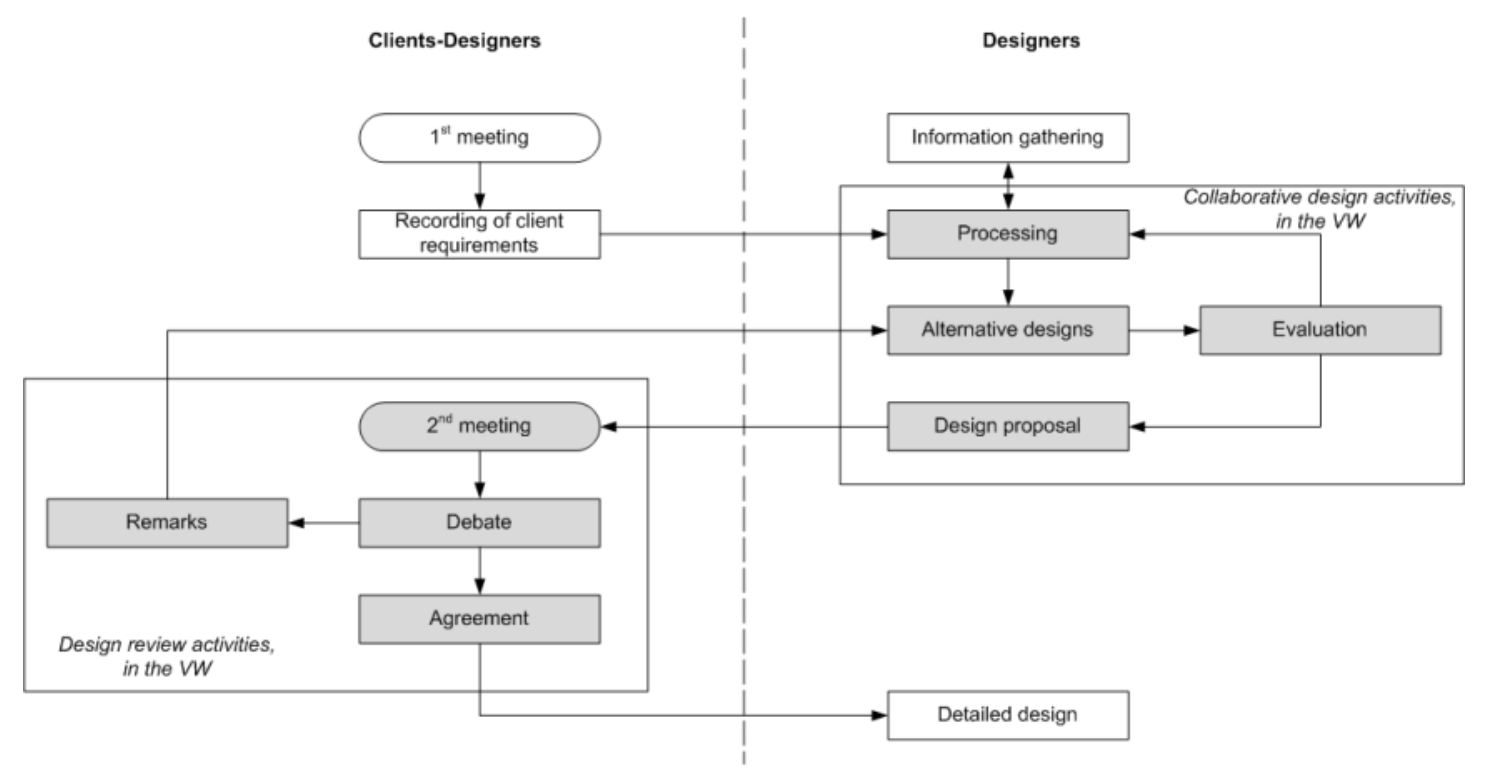

Figure 2: Outline of the process of design collaboration for the design review of a cottage: the steps within the 'communication method' occurred in the VW.

The design collaboration process occurred both outside and inside the VW (Figure 2 shows an overview of the process as constructed during the activity). The VW sessions held were 4 in total; 2 for each couple of clients. In the first session the clients entered the VW, walked through the space and asked questions, discussed and provided comments on the design. For the first group of clients this lasted for 54', and 
for the second group 40'. In the second session, the lead designer worked on his own in the VW to provide corrections: for the first set of corrections he required 52' and for the second set 68 '.

The study focused on the part of the design process after the design team had completed a first design of the cottage. The clients were asked to log into the system and review the designed cottage in a similar way as a real-life meeting, only this time with the use of VW tools. Users were asked to choose whichever tools they deemed more appropriate for the actions they wished to perform.

\subsubsection{Results and assessment}

We have employed a mixed method for data collection and analysis of collaborative design activity in the VW including: observation, questionnaires and dialogue analysis. The results of this study can be grouped into the following dimensions: (a) support of collaborative design review of architectural design in VWs; (b) quality of communication of design participants in the VW (with respect provided VW tools and available affordances); and (c) the user experience.

We found that VWs can support the design review of architectural design at the level of conceptual designing effectively with respect to the time required to reach to solution, and fruitfully with respect to yielding useful client requirements and corrections. The quality of communication tools provided was satisfactory mainly in terms of the richness of the environment; however a number of usability issues were identified. Notwithstanding usability issues, the user experience was quite enjoyable and satisfactory for all participants (this is something found in all three studies).

Regarding the outcome of the design review, both design review sessions produced a considerable number of proposed changes by clients. These changes were grouped into two categories: simple and complex on the basis of how complicated was the procedure of applying the new solution. Each couple of clients identified quite different sets of changes according to their requirements: the first couple identified six (6) simple and one (1) complex changes, and the second couple seven (7) simple and two (2) complex changes. For each required change, a detailed list of data was recorded (Error! Reference source not found.). Furthermore, usage data of available 
communication tools was recorded and evaluated on the basis of criteria like: 'total uses of', type of communication task (simple/complex), etc. The requirements of the two client couples were naturally different; what is important is that the collaborative design review session in the VW yielded important alterations from the client side with the use of various built-in and designed communication tools.

Table 2: An aspect of the data collected from the two client couples for the collaborative cottage design review in the VW.

\begin{tabular}{|c|c|c|c|c|c|}
\hline \multicolumn{6}{|c|}{$\mathbf{1}^{\text {st }}$ client couple } \\
\hline Asked alteration & $\begin{array}{c}\text { Alteration } \\
\text { complexity }\end{array}$ & Involvement & Time & Media & Total no. of uses \\
\hline \multicolumn{6}{|c|}{ Synchronous communication (30', direct communication time: $\left.13^{\prime}\right)$} \\
\hline Additional of railing & simple & 1 client-architect & $1: 30$ & $\begin{array}{l}\text { Voice chat } \\
\text { Point }\end{array}$ & $\begin{array}{c}17 \\
6\end{array}$ \\
\hline Place for a boat & simple & 1 client - architect & $2: 10$ & $\begin{array}{l}\text { Voice chat } \\
\text { Collab. board } \\
\text { Voice chat }\end{array}$ & $\begin{array}{c}7 \\
2 \\
14\end{array}$ \\
\hline New kitchen door & simple & 2 clients-architect & $2: 20$ & $\begin{array}{l}\text { Point } \\
\text { Collab. board }\end{array}$ & $\begin{array}{l}5 \\
1\end{array}$ \\
\hline Stair at the platform & simple & 2 clients-architect & $1: 40$ & $\begin{array}{l}\text { Voice chat } \\
\text { Collab. board } \\
\text { Voice chat }\end{array}$ & $\begin{array}{c}5 \\
1 \\
29\end{array}$ \\
\hline Storage room & complex & 2 clients-architect & $5: 10$ & $\begin{array}{l}\text { Collab. board } \\
\text { Point }\end{array}$ & $\begin{array}{c}3 \\
11\end{array}$ \\
\hline \multicolumn{6}{|c|}{ Asynchronous communication } \\
\hline Bigger balcony & simple & 1 client & - & $\begin{array}{l}\text { Annotation } \\
\text { Area marker }\end{array}$ & $\begin{array}{l}1 \\
1\end{array}$ \\
\hline Change roof type & simple & 1 client & - & Annotation & 1 \\
\hline \multicolumn{6}{|c|}{ 2nd client couple } \\
\hline Asked alteration & $\begin{array}{l}\text { Alteration } \\
\text { complexity }\end{array}$ & Involvement & Time & Media & Total no. of uses \\
\hline \multicolumn{6}{|c|}{ Synchronous communication (30', direct communication time: $15^{\prime}$ ) } \\
\hline Change railing type & simple & 1 client-architect & $0: 40$ & Voice chat & 6 \\
\hline Change door material & simple & 1 client-architect & $2: 10$ & $\begin{array}{l}\text { Voice chat } \\
\text { Texture library* } \\
\text { Voice chat }\end{array}$ & $\begin{array}{c}4 \\
3 \\
18\end{array}$ \\
\hline Bigger kitchen & complex & 2 clients-architect & 4:00 & $\begin{array}{l}\text { Collab. board } \\
\text { Point }\end{array}$ & $\begin{array}{l}2 \\
9\end{array}$ \\
\hline $\begin{array}{l}\text { Mezzanine above } \\
\text { living room }\end{array}$ & simple & 1 client - architect & $0: 50$ & $\begin{array}{l}\text { Voice chat } \\
\text { Point } \\
\text { Voice chat }\end{array}$ & $\begin{array}{c}6 \\
4 \\
32\end{array}$ \\
\hline Change wall colours & complex & 2 clients-architect & $6: 20$ & $\begin{array}{l}\text { Point } \\
\text { Colour palette* }\end{array}$ & $\begin{array}{l}7 \\
5\end{array}$ \\
\hline Move window & simple & 1 client-architect & 0.30 & $\begin{array}{l}\text { Voice chat } \\
\text { Point }\end{array}$ & $\begin{array}{l}4 \\
3\end{array}$ \\
\hline Change roof material & simple & 1 client - architect & $0: 40$ & $\begin{array}{l}\text { Voice chat } \\
\text { Texture library* }\end{array}$ & $\begin{array}{l}3 \\
3\end{array}$ \\
\hline & & nchronous commu & cation & & \\
\hline New balcony & simple & 1 client & - & $\begin{array}{l}\text { Annotation } \\
\text { Collab. board }\end{array}$ & $\begin{array}{l}1 \\
1\end{array}$ \\
\hline Change roof type & simple & 1 client & - & Note board & 1 \\
\hline
\end{tabular}




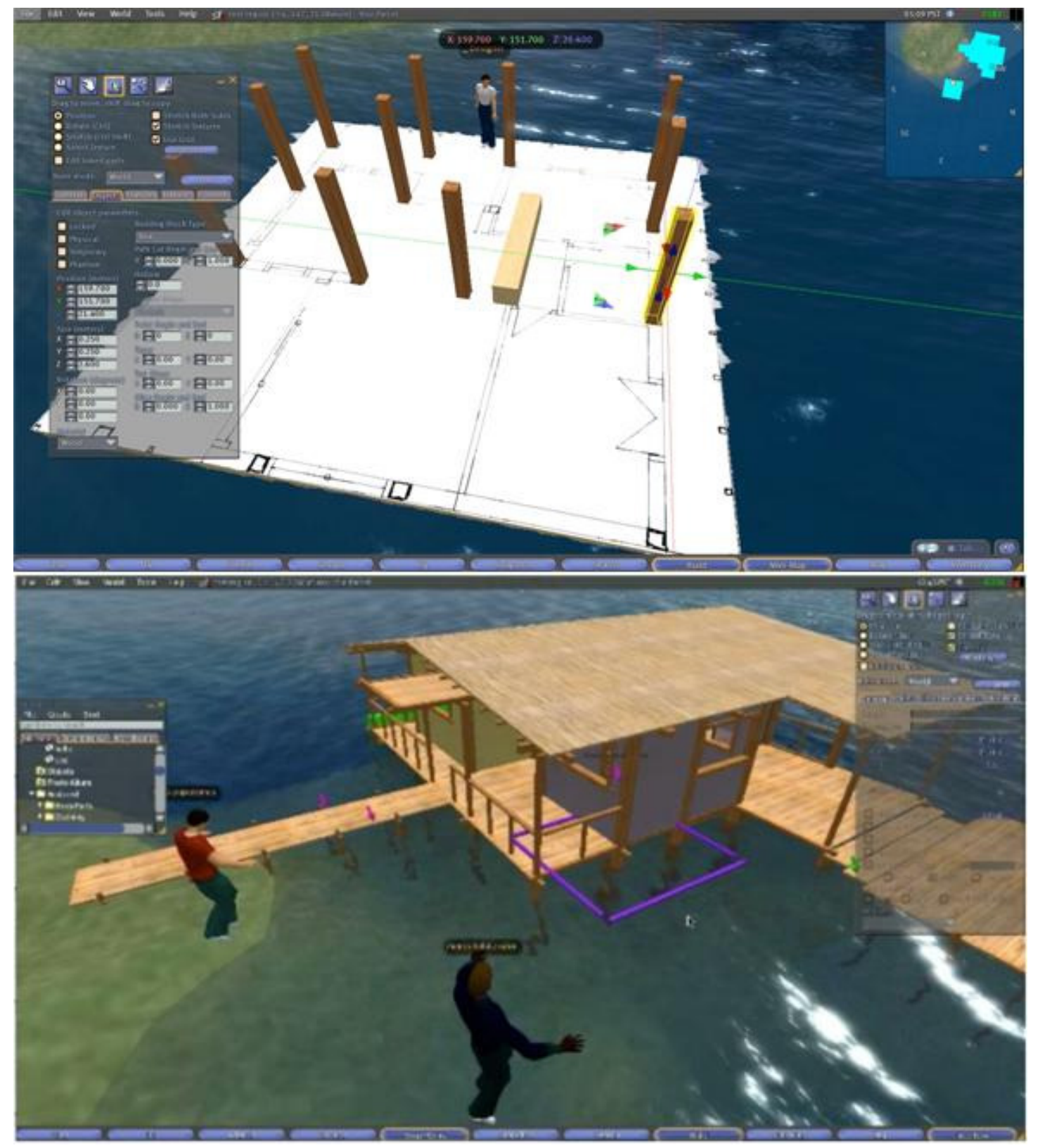

Figure 3: Participants in the VW during the collaborative design / design review of the cottage.

Regarding the quality of communication during this collaborative design review activity, we kept track of communication tools (e.g. chat) and affordances (e.g. pointing) used for design participant interaction in the VW. For example, Error! Reference source not found. shows the alterations requested from the client couples along with the communication tools used for expressing these requests. It is not the purpose of this paper to present an extensive account of these more specific results regarding the use of communication tools in the VW; however the main results may be summarized into that: (a) The use of additional VW tools provided was much more 
intensive for complex remarks rather than for simple ones; (b) The collaborative board tool was mainly used during synchronous communication, while the clients used area marker and note board in asynchronous communication modes. (c) For simple alterations clients attempted to mark their remarks independently (without consulting one another or the designer), while for making complex annotations they asked their mate's help and the chief designer's opinion. (d) All users customised their avatar as soon as they logged into the system, although they were never asked to do so. The major problem identified in this respect was that VWs have not yet developed sophisticated and easily customisable ways to present several types of feedback and information to the user, with the consequence that sometimes users were not sure if their actions had been recorded in the environment (e.g. if their annotations had been saved), with the consequence that they needed to perform a number of verification actions that wouldn't be required in a more user friendly environment.

Regarding the user experience, all users were enthusiastic with the environment. They showed a high degree of commitment to the task and engagement to the environment. All users urged to correct their appearance and explore the environment at first which is a deeply grounded behaviour of all humans when we find ourselves in new spaces and places. On the other hand users faced a number of usability problems; indeed there are many usability issues in 3D interaction with VWs and all participants - but the chief designer - were not expert users. The results of other studies with respect to user experience were quite similar.

\subsection{Case study 2: Design team collaborations for the interior space design of an academic laboratory with focus on situation awareness}

\subsubsection{Goal, Focus, Participants and Process}

The goal of the second VW design study was the interior space design of an academic laboratory (lab of materials in design) that should also afford teaching activities. The study focused on the assessment of the quality of situation awareness mechanisms in design collaborations in VWs. Situation awareness has been defined by Endsley (1988) as "the perception of the elements in the environment within a volume of time and space, the comprehension of their meaning and the projection of their status in 
the near future" and it provides a primary basis for decision-making performance and user experience of design participants in VWs.

The participants were a total of eight (8) persons with the following roles:

- One member of the research team, who facilitated the process providing help and performing observation and evaluation.

- Two (2) design teams of three (3), between 24 - 36 years old who carried out the activity independently. One team consisted of professional interior space designers and the other of graduates from the Department of Product and Systems Design Engineering, University of the Aegean, Greece.

- One client, who is a lecturer of the department, participated in providing requirements (outside the $\mathrm{VW}$ ) as well as in the evaluation of the final outcome of the process (inside the VW). 


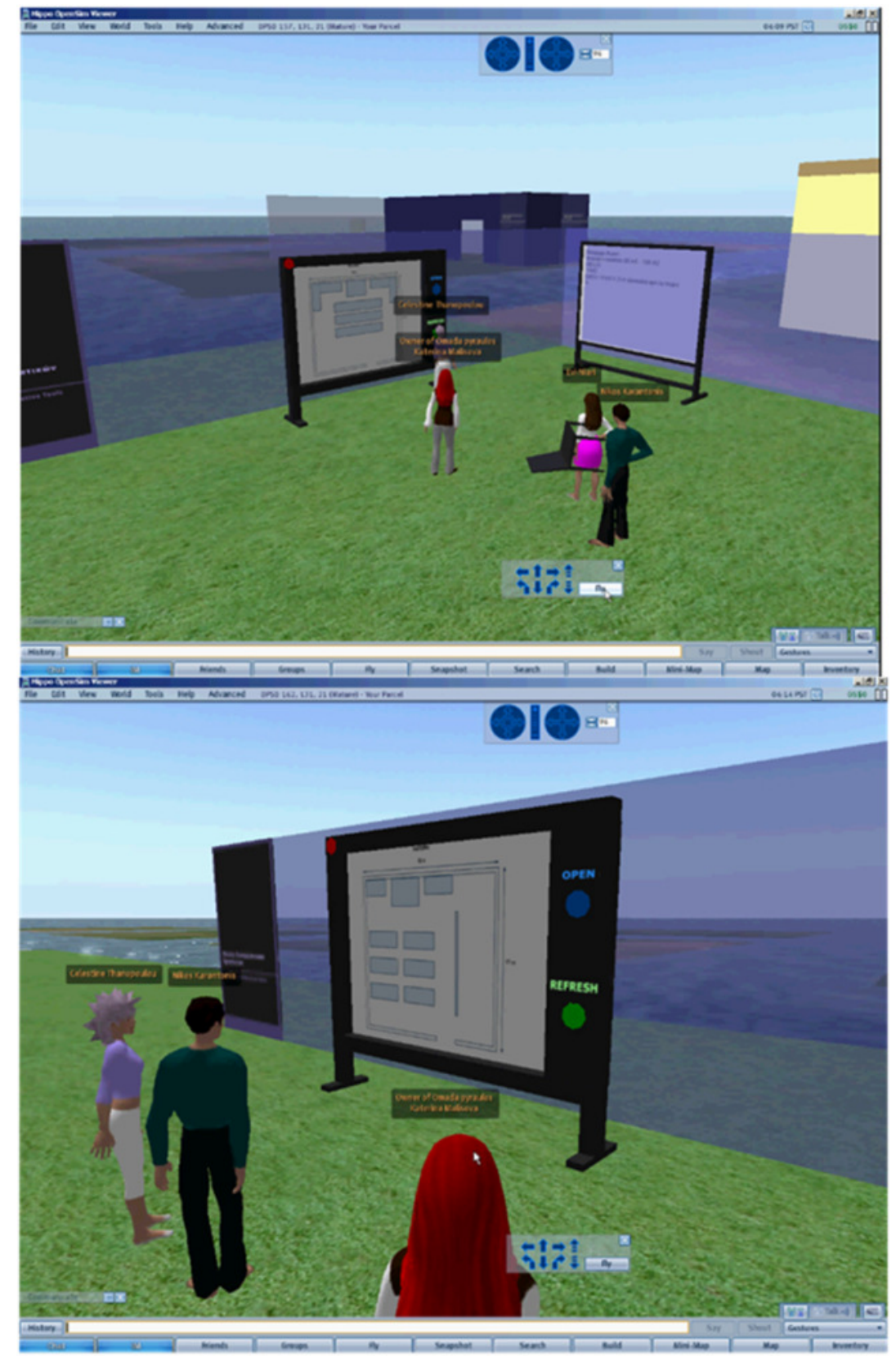

Figure 4: Two tools for supporting collaborative design activities in VWs: collaborative diagram board and message board.

Besides the available tools for the creation of 3D objects in the VW, two additional tools were designed to further support the collaborative design process (Figure 4): (a) a drawing board and (b) a message board. The drawing board tool was provided to interior designers especially for sketching their concepts for the structure of interior space by providing an online connection to a Google Docs document for sketching. The message board tool was provided for writing decisions, comments on ideas, design guidelines and notes during the whole design process. 


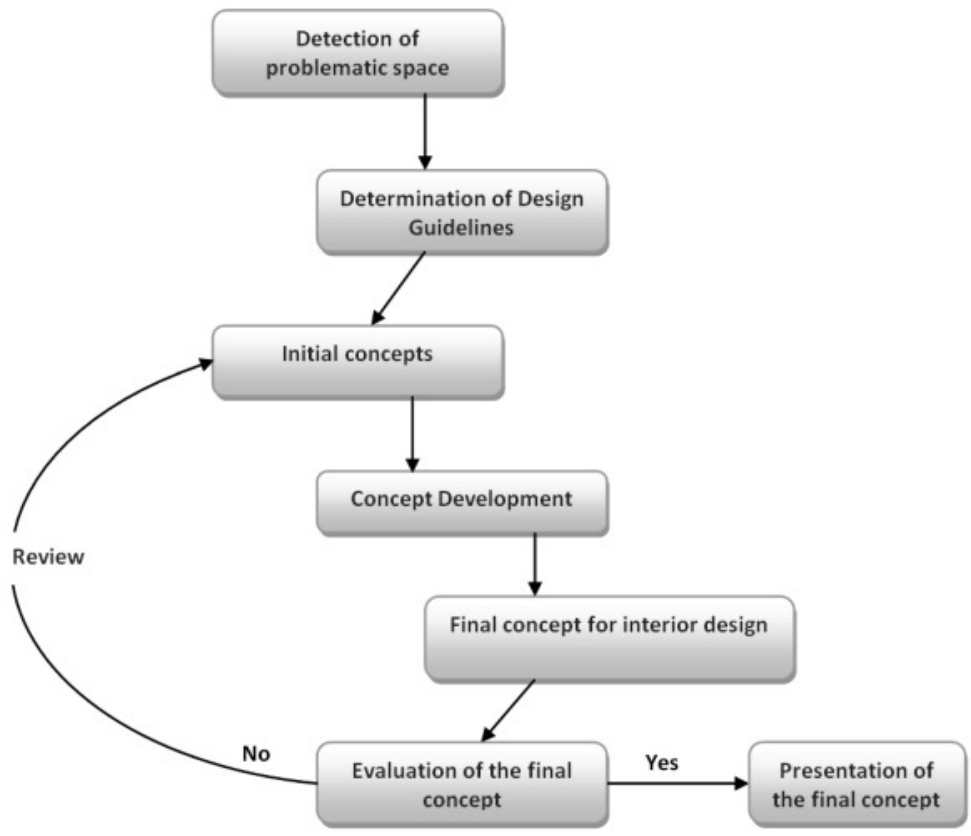

Figure 5: Flowchart of the interior design process.

The process of carrying out the design collaboration lasted a total of $4 \mathrm{~h}$ for each group including the VW training, and involved the following phases:

1. Determination of design guidelines: this happened outside the VW with an interview with the client.

2. Training session in the $\mathrm{VW} \sim 30$ ' 


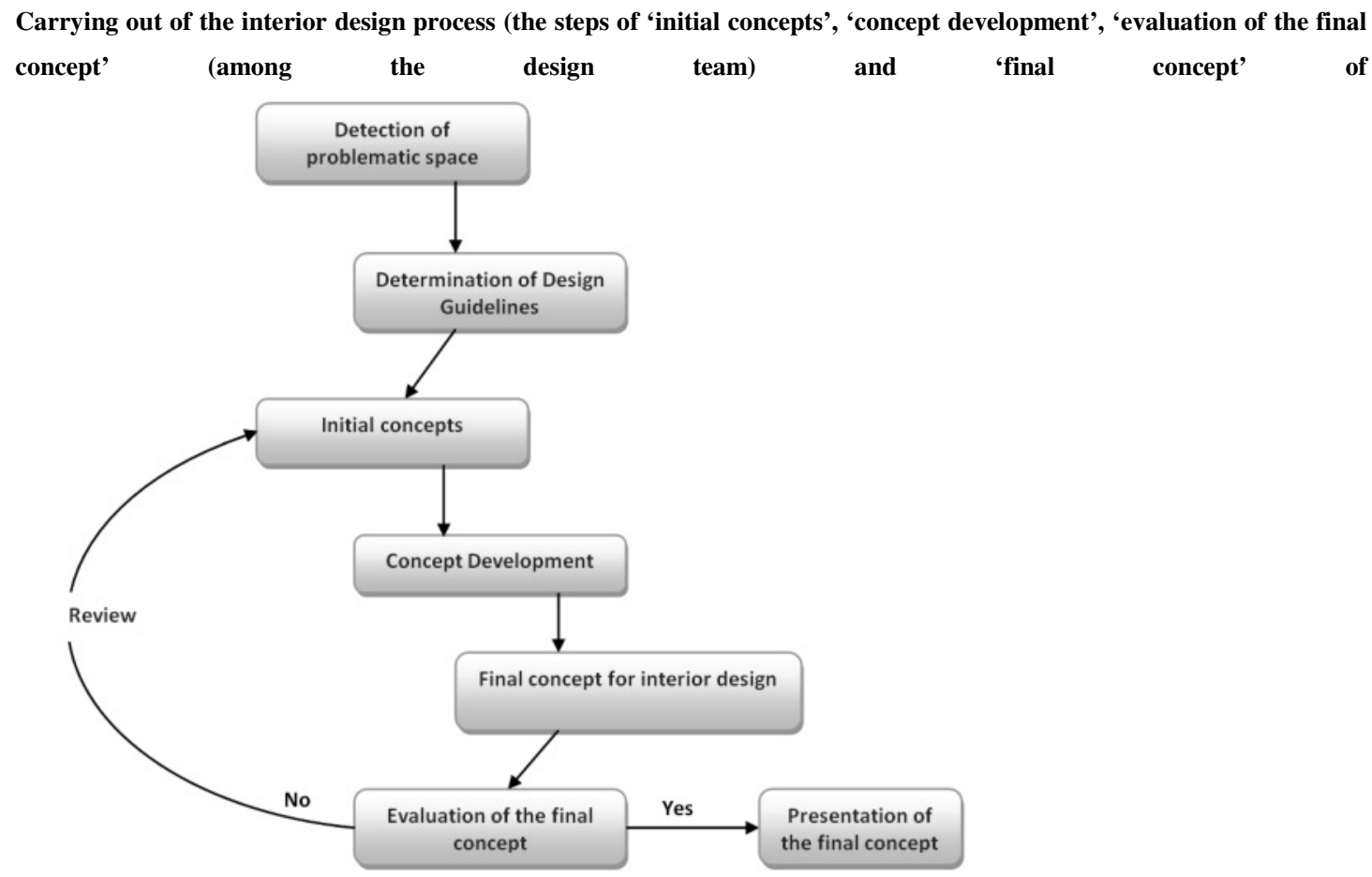

3. Figure 5) $\sim 2,5 \mathrm{~h}$

4. Observation of the design process (a member of the research team) - in parallel to step 3 above.

5. Debriefing and questionnaires (the member of the research team with the designers) 30'

6. Design Review (the client walked through each academic lab interior along with the design teams and provided feedback and remarks) 30'

\subsubsection{Results and assessment}

We have employed a mixed method for data collection and analysis of collaborative design activity in the VW including observation, questionnaires and interviews with design participants. The results of this study can be grouped into the following dimensions: (a) support of collaborative interior space design in VWs; (b) the user experience; and (c) the quality of situation awareness of design participants in the VW (with respect provided VW tools and available affordances).

Overall, we found that VWs can support the collaborative interior design process effectively with respect to the time required to reach to a conceptual solution and the 
quality of these solutions. In particular, both design teams reached to a conceptual interior design of the academic lab within a total time of 2.5 hours. Also, both designed academic lab were well-accepted by the client with not major requests for alterations - however the task was not that complex in comparison to other cases of interior design that have intense service design (Saco \& Goncalves, 2008) requirements (like for example places offering customer and hospitality services). Regarding user experience, all designers found it quite pleasant and fruitful; some were expert users of VWs - these did not face many usability issues and helped their mates.

The focus of this study was on the situation awareness of design collaborators in VWs. To investigate the quality of situation awareness it was first required to identify the most significant VW affordances, tools and feedback mechanisms and then to assess these during the collaborative design situations. Following the suggestion of Salmon et al (2006) who recommend that a multiple techniques' approach may be the most appropriate way to measure situation awareness in computer-based collaborative environments, we have adapted the SABARS (Situation Awareness Behavioural Rating Scale) technique in which an expert observer assigns ratings and remarks about participants' situation awareness to mechanisms of the environment combined with the PSAQ (Participant Situation Awareness Questionnaire) technique in which participants' subjective judgments for their perceived awareness are provided. Both techniques are proposed by Matthews et al (2000).

An overview of findings regarding situation awareness in collaborative design in VW, as identified by the $2^{\text {nd }}$ case study is summarized in Table 3 . For each phase of the process (column 1), the major problems of situational awareness are identified (column 2) with respect to related VW affordances, tools and feedback mechanisms (column 3). Furthermore, workarounds followed by designers to cope with these problems were tracked down (column 4) as well as ideas for improved awareness mechanisms (column 5). The results outlined in Table 3 suggest that considerable number of situation awareness issues was identified, however for most of them workarounds were quickly applied, with some exceptions for organizational tasks. Some of these issues and recommendations, like the resources and annotation tools 
(2nd and 12th recommendations in Table 3), have been addressed with additional tool design and development for the 3rd case study.

Notwithstanding the identified awareness issues, designers reported that they had a satisfactory awareness of the VW environment after the collaborative design activity. They perceived and understood their other mates' actions in the VW fast, this allowing them to coordinate their moves and actions as well as in taking the initiative to communicate and ask questions. They also reported that the VW helped them monitor others' progress which motivated them to progress with their own responsibilities. In addition, it was identified that in cases when designers focused on their own tasks in their digital places, it was easy to return to the collaborative space and catch up with their other mates' work progress (due to the persistence of VWs). 

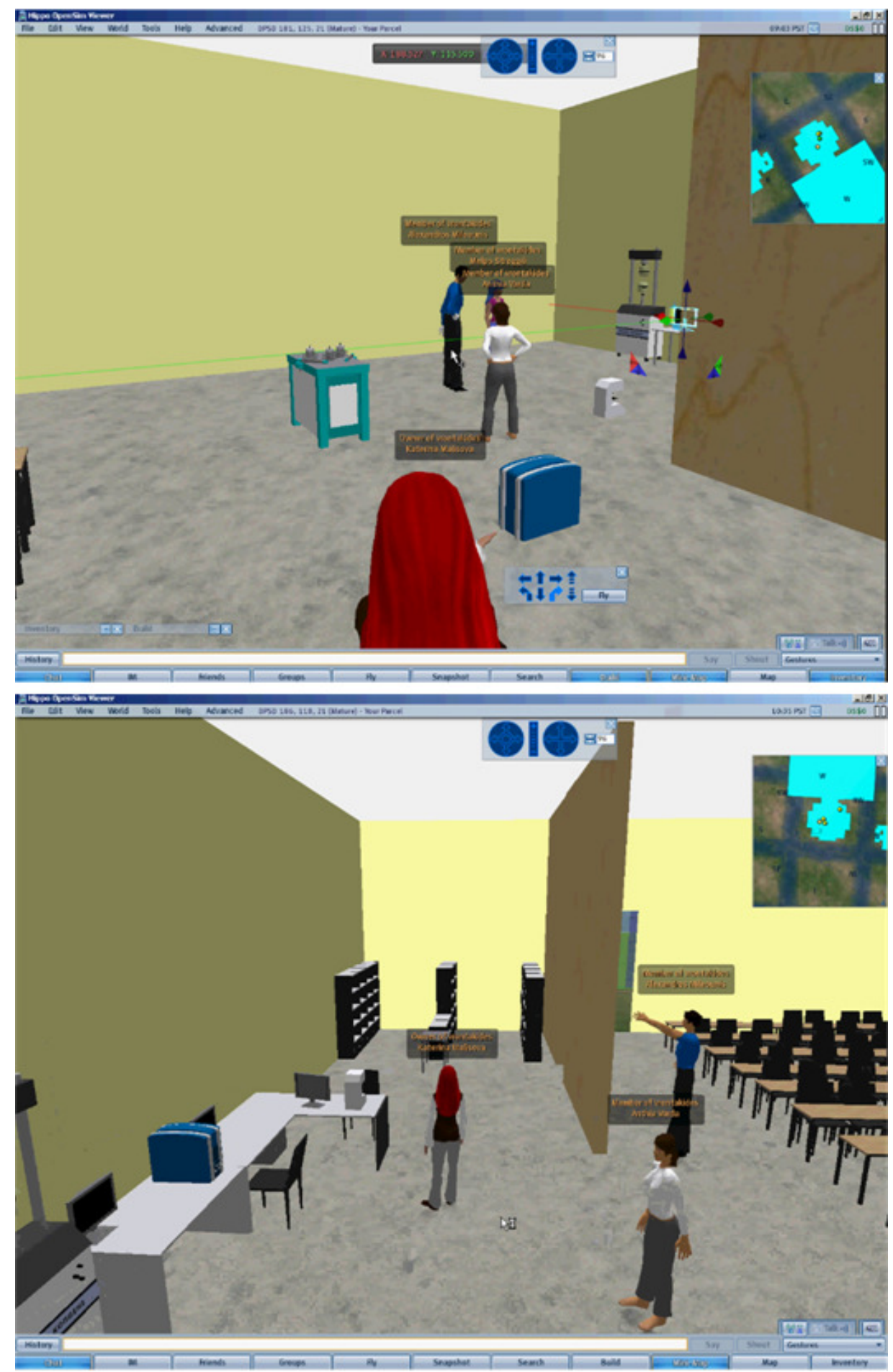

Figure 6: (a) The design team while working (and a member of the research team observing); (b) The academic lab created with rooms for teaching and scientific equipment. 
Table 3: Overview of findings regarding situation awareness in collaborative design in VW, as identified by the $2^{\text {nd }}$ case study.

\begin{tabular}{|c|c|c|c|}
\hline $\begin{array}{l}\text { Design process } \\
\text { phase }\end{array}$ & Major problems of situation awareness & $\begin{array}{l}\text { Related VW } \\
\text { affordances, tools and } \\
\text { feedback mechanisms }\end{array}$ & Workarounds \\
\hline Initial concepts & $\begin{array}{l}\text { 1. Remember the list of client guidelines and to look at } \\
\text { collected resources (e.g. Web documents) }\end{array}$ & Message board & $\begin{array}{l}\text { Voice chat; view documents } \\
\text { outside the VW }\end{array}$ \\
\hline Initial concepts & 2. What were the previous sketches of an artifact? & Drawing board & $\begin{array}{l}\text { Search for this in Google } \\
\text { docs versions }\end{array}$ \\
\hline Initial concepts & $\begin{array}{l}\text { 3. Viewing the sketches of colleagues only after } \\
\text { refreshing the screen }\end{array}$ & Drawing board & None. \\
\hline $\begin{array}{l}\text { Concept } \\
\text { development }\end{array}$ & 4. Who just edited an object? & $\begin{array}{l}\text { Feedback mechanisms for } \\
\text { others' actions }\end{array}$ & Voice chat \\
\hline $\begin{array}{l}\text { Concept } \\
\text { development }\end{array}$ & $\begin{array}{l}\text { 5. What is the history of this object? (who created it, who } \\
\text { re-designed it, where there different versions, etc) }\end{array}$ & VW object properties & Voice chat \\
\hline $\begin{array}{l}\text { Concept } \\
\text { development }\end{array}$ & $\begin{array}{l}\text { 6. To see the dimensions of an object is a tedious and } \\
\text { repetitive task }\end{array}$ & $\begin{array}{l}\text { VW affordances for } \\
\text { seeing object dimensions }\end{array}$ & None. \\
\hline Final concept & $\begin{array}{l}\text { 7. Uncertain about the accuracy with which the objects } \\
\text { were placed in space. }\end{array}$ & $\begin{array}{l}\text { VW affordances for } \\
\text { object placing }\end{array}$ & None. \\
\hline Final concept & $\begin{array}{l}\text { 8. Lack of support for defining locked and unused space } \\
\text { around an object for ergonomic purposes. }\end{array}$ & VW object properties & Voice chat \\
\hline Final concept & $\begin{array}{l}\text { 9. The true scale of objects and space makes them look } \\
\text { small in the VW }\end{array}$ & VW environment & $\begin{array}{l}\text { Adjust avatar height; view } \\
\text { VW in first person view }\end{array}$ \\
\hline Final concept & $\begin{array}{l}\text { 10. Uncertain of whether subsequent (part of) objects } \\
\text { were tangential to each other. }\end{array}$ & $\begin{array}{l}\text { VW affordances for } \\
\text { assembly tasks }\end{array}$ & $\begin{array}{l}\text { Walk around and/or } \\
\text { tediously inspect objects }\end{array}$ \\
\hline All phases & 11. Vague mini-map of others' positions and activity & VW mini-map & $\begin{array}{l}\text { Walk/fly to see or voice/text } \\
\text { chat }\end{array}$ \\
\hline All phases & $\begin{array}{l}\text { 12. Uncertain about coordination of their own actions } \\
\text { with respect to others' tasks (what do I have to do next?) }\end{array}$ & VW/Drawing board & Voice chat \\
\hline All phases & $\begin{array}{l}\text { 13. Hard for participants to make use of gestures for their } \\
\text { avatar. }\end{array}$ & $\begin{array}{l}\text { VW affordances for } \\
\text { gesturing }\end{array}$ & Voice chat \\
\hline All phases & 14. Not visible role of others during particular tasks & $\begin{array}{l}\text { Drawing board / Avatar } \\
\text { appearance in the VW }\end{array}$ & None \\
\hline All phases & $\begin{array}{l}\text { 15. Notifications about text chat, when collaborators } \\
\text { where far away (text chat range is geographically limited) }\end{array}$ & VW text chat & $\begin{array}{l}\text { Voice chat or 'shout' VW } \\
\text { function }\end{array}$ \\
\hline
\end{tabular}

\subsection{Case study 3: Design team collaborations for user interface design of a multimedia kiosk with focus on problem-based collaborative learning}

\subsubsection{Goal, Focus, Participants and Process}

The goal of the third VW design study was the design of the user interface of a multimedia kiosk system for browsing available rooms to let in the island of Syros, Greece; the intended users are tourists (Greeks and foreigners), who can access the system from the harbor. 
The focus of this case study is different from the previous two in the sense that we did not only want to study the design collaboration process itself, but also the affordances of VWs for a problem-based learning (PBL) process. In PBL students learn by addressing ill-defined and open-ended problems and reflecting on their experiences, thus developing problem-solving strategies and building domain knowledge in a selfdirected manner. Although an educational case, this collaborative design situation is authentic in the sense that the problem is related to practice and students have to contact clients and end-users; in addition students are required to become responsible for their own learning both atomically and in groups; last but not least the participating students were at the last year of study at a 5-year design engineering program, therefore possessing some experience in design project development.

The following aspects of quality assessment were addressed: (a) task performance; (b) group functioning, (c) social support, and (d) learning performance and outcome. The learning goals of the intervention were: a) to discover the usability and accessibility requirements of touch screen interfaces, b) to understand the differences in the design of such interfaces compared to other, more conventional cases, and c) to apply this knowledge in a specific practical context. The participants of the study were:

- Three (3) groups of a total of ten (10) students (3 male, 7 female; 21-26 year old) of the University of the Aegean, Greece; these groups comprised the design teams and worked independently.

- Two (2) members of the research team (who are also the students' instructors). The members of the research team helped the students during their interactions in the world, and also played the role of expert evaluators (the designs were also evaluated by the students themselves to some degree).

The construction of a working user interface prototype requires a lot of programming effort using the VW's scripting language, which was outside the scope of our design activity. We have therefore designed and implemented a number of additional tools that were available to students during the study in order to overcome these obstacles and to enhance the collaboration affordances of the environment. The implemented tools were: (a) Resource: an object that links to external web resources; (b) Comment 
recorder: a tool to record and playback user messages; (c) Annotation: an object that contains a written message; (d) InterfaceElement: an object with scripted behavior that can be used as a user interface component in the working prototype.

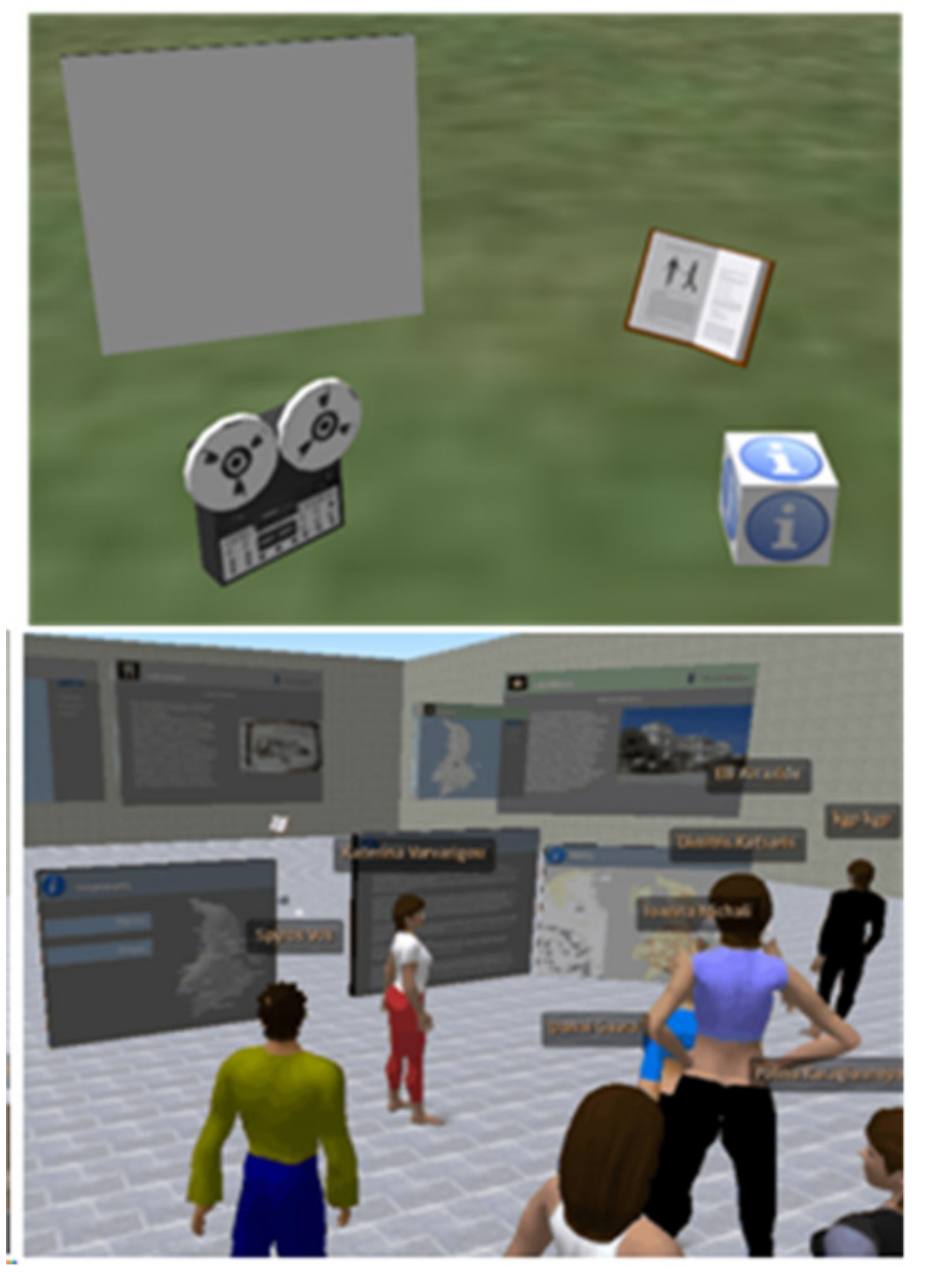

Figure 7: On the left: the supporting tools of the environment. a. Interface Element, b. Resource, c. Comment Recorder, d. Annotation. On the right: Group presentation inside the VW.

The collaborative design and learning process, which lasted for about 6.5 hours in total, included the following steps:

1. Introductory tutorial session in using the VW and the tools. $\sim 2 \mathrm{~h}$

2. Group work inside private spaces, where the problem was analyzed, ideas where shared and discussed and resources were gathered (e.g. content for the interfaces, guidelines, etc.). $\sim 2 \mathrm{~h}$ 
3. Construction of a user interface prototype as a proposed solution (one for each group). $\sim 1 \mathrm{~h}$

4. Once the group agreed on the final prototype, they attached explanatory annotations to justify their design choices and presented it to the whole class. $\sim 45$

5. Students and instructors were then free to test each interface prototype themselves and leave comments and suggestions concerning the appropriateness of the solution. $\sim 45$ '.

\subsubsection{Results and assessment}

We have employed a mixed method for analysis of problem-based learning collaboration in VWs, which collects data from: (a) automated monitoring of student behaviour (video capturing of various stages of the activity within the VW; logfile analysis about the use (time to build, deleted elements, etc.) of the tools; and observation of the state of the VW during and after the exercise); (b) dialogue analysis (voice chat was recorded for most of the exercise: the collaboration tasks, not the final presentation); (c) students' self-reporting (questionnaires and follow-up discussion).

The results of this study can be grouped in the following dimensions: (a) support of collaborative user interface design in VWs; (b) quality of the PBL learning experience in the VW; and (c) the collaborative design and learning experience, which was fruitful for all participants despite some usability problems faced with the use of some aspects of the VW.

We found that VWs can effectively support user interface design of multimedia kiosks at the level required to reach to a counterpart of a rough screen design (Brown, 2010) and at a level that can be evaluated by expert-based (e.g. a cognitive walkthrough (John \& Packer, 1995) or a heuristic evaluation (Nielsen \& Molich, 1990)) or user-centred formative HCI evaluation methods similar to those of paper prototyping (Snyder, 2003). All three teams achieved the goal of the design (i.e. to provide the design of the user interface of an information kiosk), at a fairly satisfactory level. All teams demonstrated interesting designs that took related 
guidelines and content into account. However they all reported that they would need more time to elaborate more their design solutions.

The whole process lasted for a total time of 6.5 hours, which was about 1.5 hour more than initially estimated. The first 2 hours were devoted to the tutorial about the use of the VW. Then, a total of 3.5 hours were devoted to the activity of user interface design, presentations and follow-up; a total of 1 hour was allocated to the breaks. Participants were asked how much time they would need to carry out the user interface task in a 'face to face' situation and deliver at the same quality: some of them answered about the same time (3.5 hours), others said about an hour less. This is a quite interesting result considering other time consuming activities in face to face situations like for example time arrangements.

With respect to the design collaboration and related actions taken, we observed that students devoted a large portion of their available time to discuss about the design problem. These were intertwined with intervals of self-directed learning, which occurred either from 'assignments' or 'requests' by other team mates (e.g. "will you find photos and content about hotels?") or from individual initiative (e.g. "I can find some text to write about Syros history"). This was also identified by the dialogue analysis (following the taxonomy of Fussell et al, 2000) (Fig. 4): most of discussion was about the procedure and task coordination (38.7\%) and acknowledgements (24.0\%), while less time was devoted to discuss about the task status $(6.2 \%)$ and to refer to virtual objects and tools $(11.0 \%)$.

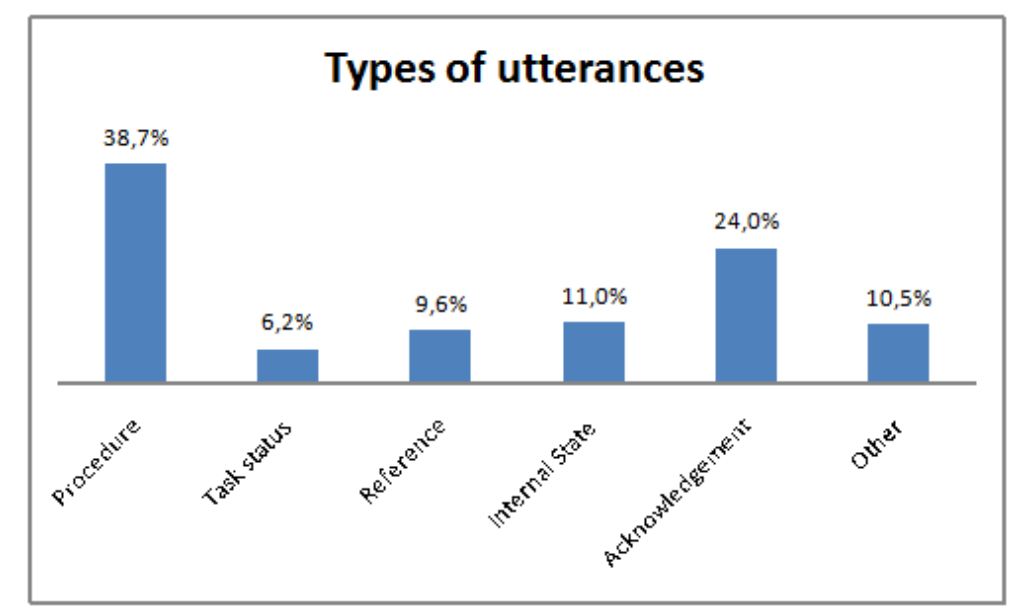

Figure 8: Types of utterances during the collaborative design and learning activity in the VW. 
All teams exhibited active interaction skills with respect to monitoring the progress of group work; this was evident especially from dialogue analysis: a rather large number of utterances were questions about how to proceed with the activity and specific tasks $(14.1 \%)$, while there were also a large number of acknowledgements $(24.0 \%)$ of group work. Each team used a different style of coordination of the work. One team demonstrated a totally balanced coordination scheme without someone taking up a leading role. The other two teams quickly established a leader (in both cases the person who had more experience with the use of the VW) and allocated roles during the collaboration: the main roles were those of the 'visual designer', who also sketched the layout of the screens and the 'content designer' who located and edited content (mainly images and text). All participants reported that the result of their work was a collaborative product and that the environment contributed to their collaboration. A detailed account of results of this case study is presented in (Vosinakis et al, 2011a; Vosinakis et al, 2011b).

\section{Discussion and Conclusions}

In this paper we have provided an account of the value of VWs for collaborative design having explored their use through case studies that involved designers and clients in pragmatic and authentic design situations. We have described our approach on the basis of principles for study design that follow a reflective and social perspective about designing and practices in $\mathrm{CMC}, \mathrm{CSCW}$ and $\mathrm{HCI}$ evaluation and user experience studies. In this respect we distinguish our approach from experimental approaches that focus on the exploration of design thinking through technology, because we are interested in examining the degree to which VWs affordances and tools can contribute to phases and activities of authentic collaborative design projects that involve designers' cooperation and client feedback.

The experience gained from the three case studies presented is supportive of the argument that VWs can be a prospective medium for collaborative design in various stages and activities. VWs are not just the means to perform common tasks successfully in a new environment, but they also present considerable added value by integrating several qualities. However, being a relatively new medium it also introduces new paradigms and metaphors, and users have to invest time and effort in 
it in order to fully exploit its powerful potential. Also, given the limited number of similar design studies in VWs, more research is needed in order to reveal their potential and to discover meaningful ways of using them in practice.

The results of the case studies suggest that VWs can effectively support conceptual design activities in the domains examined. While immersed in the environment, designers have constructed simple or more complex structures by adding new content and by instantly manipulating and arranging 3D objects. Furthermore they have uploaded complementary sketches, drawings or images in the form of image files and embedded them in the environment to assist them during their design process. VWs are open-ended environments that attract users to experiment with them. Thus, their value is that they allow the co-creation of concepts in an engaging and motivating environment and therefore, when conceptual design has to occur in teams a VW collaborative design studio is certainly an option. Also, VWs offer empowerments to users, in the sense that some laws physics (like gravity) can be bypassed, which can lead to interesting ideas in some domains of design (e.g. flying around a designed artifact or seeing it in third person view ('God' view) is fairly simple to do).

In addition, we have seen that VWs can be effectively employed in design review and customer-centred evaluation of conceptual design in the domains examined. Designers and clients have had the chance to evaluate and review the prototypes presented in the environment by navigating their avatar through the content and observing it in natural dimensions. This is an interesting finding especially if we take into account that conceptual designing is the most critical phase of the design process (Cross, 2008) and that there are true obstacles in client participation at this phase. We have found in all three case studies that the outcome of the collaborative design activity was interesting for clients and yielded constructive comments. In addition, the user experience was quite engaging in all three studies for all participants and especially for clients who did not face severe usability problems - since that it was mainly required from them to navigate in the virtual place. Thus, VW can add value in the design review and evaluation phases of design activities, especially for cases and domains of design for which customer participation and feedback is critical for the success of the process and outcome. Certainly, more studies that those presented 
in here are required to strengthen this conclusion; a few can already be found in the bibliography, e.g.: (a) the work of Mobach (2008) who presents a participatory design approach combining VWs as a meaningful, valuable, and affordable approach to cocreate better organizational and interior spaces for the case of two pharmacy buildings; (b) the comparative study of Madathil \& Greenstein (2011) who report that VWs can be used for synchronous remote usability studies with similar effectiveness to web conferencing and co-located laboratory testing.

Another remark is that the VW platform used in our case studies could not adequately support detailed design activities regarding the form, structure and physical behavior of an artifact. The design artifacts lacked visual detail and rendering quality, according to some participants. This was an expected result, since most in-world modeling tools in today's VWs have very limited functionality compared to sophisticated 3D modeling applications. Furthermore, a simulation of an object's physical behavior and functionality can only be trivial and definitely far from realistic in VWs. Both problems of rendering and simulation quality are related to the nature of VWs being dynamic, real-time environments.

An additional, equally important finding from our case studies was the fact that VWs proved to be a satisfactory collaboration environment for designers and provided increased communication and awareness. The quality of collaboration between the design team and between designers and clients is a critical factor for the success of design activities. VWs offer a high degree of awareness of others (and their actions), which is highly stimulating for collaborative design and they incorporate a fusion of communication and presence affordances that motivates users to communicate. The participants in the case studies could effectively communicate, coordinate their work and be aware of each others' activities during their tasks in the VW. Besides text and voice communication they also used non-verbal communication cues through their avatars to point to places or object. Furthermore they used tools, artifacts and annotations to communicate their comments and requirements concerning the design concepts.

The results of the case studies suggest that VWs can support collaborative conceptual design effectively in the domains examined: architectural design, 
interior design and user interface design. What is common in these domains is the fact that the emphasis of design is on the form and structure, rather than on sophisticated functions or processes. In architectural and interior design, the concept could be formulated by constructing a place and reviewed by walking around the designed place, observing the arrangement of furniture and appliances and imagining oneself using the place. Similarly, in user interface design the concept has been formulated by arranging components in windows and by providing a simple point and click functionality to them. The review and evaluation of the concepts included the users' testing of the artifacts/interfaces by trying to assess their usability. A further similarity of the domains examined is that the design concept could be reached by arranging pre-existing objects in some structure and not by introducing novel forms. As stated before, the in-world modeling tools are not sophisticated enough to easily create complex 3D forms. In such cases, designers would have to create the objects in some external application and upload them to the world.

VWs are not design platforms per se, and if we want to support design activities we need to provide appropriate digital places and tools in order to discover novel ways in which this medium may positively affect design behavior and enhance the design process. Much like the Web, VWs are a platform that can be shaped according to ones needs, rather than a fixed tool. The functionality of VWs can be extended, their interaction affordances can be refined, and novel and usable tools can be built to further support collaborative design activity. This point was highlighted in our case studies. Given the appropriate tools, the potential and capabilities of the environment can be extended and more complicated and application-specific tasks may be supported.

The value of VWs for collaborative design can be increased when these are integrated with commercial applications that are commonly used by the design community, such as word processors, photo editors, drawing programs, 3D modeling programs, web browsers, etc. Some integration took place in our case studies: the VW diagram board of the second case study provided an interface to Google Docs drawings, but far more possibilities need to be explored and evaluated. This integration would be important for the success of VWs in the design process since data should be converted, 
communicated and manipulated throughout various stages. Currently, VW platforms like SL and OpenSimulator have started to support mesh import from 3D modeling programs, and Open Wonderland (another open source VW platform) supports live interface with external applications visualized as 2D windows in the VW.

We expect that in the near future the overall picture of research in collaborative design in VWs will be that of larger pragmatic projects, in which multidisciplinary teams of researchers work together on complex and realistic design tasks. The use of particular methods or methodologies for participatory and service design can be also explored, provided that it is accompanied by related tools that designers can use to document and explicate their work to their mates and clients. In addition, mixed methods for performing design studies in VWs are expected to arise making a combined use of established practices in design studies and in CMC studies, since that collaborative design studies in VWs are essentially transdisciplinary, lying at the intersection of the fields of design, collaboration, HCI and VWs.

\section{References}

Bannon, L. (1991) From human factors to human actors: The role of psychology and human-computer interaction studies in system design. In Design at Work:

Cooperative Design of Computer Systems, J. Greenbaum and M. Kyng, eds., Lawrence Erlbaum, Hillsdale, NJ, 1991.

Bartle R. (2003) Designing Virtual Worlds: New Riders-Games.

Bassiere, K. Ellis, J.B. \& Kellogg, W.A. (2009) Acquiring a Professional "Second Life": Problems and Prospects for the Use of Virtual Worlds in Business, Proc. of ACM CHI Conference on Human Factors in Computing Systems (CHI) 2009, April 4-9, Boston, MA, USA.

Benford, S., Greenhalgh, C., Rodden, T. (2001) Collaborative Virtual Environments, Communications of the ACM 44(7), 79-85.

Blackwell, A.F. (2006) The Reification of Metaphor as a Design Tool, ACM Transactions on Computer-Human Interaction, Vol. 13, No. 4, December 2006, Pages 490-530. 
Blandford, A. Cox, A.L. Cairns, P. (2008) Controlled Experiments, in Paul Cairns, Anna L. Cox (eds.) Research Methods for Human-Computer Interaction, pp. 116, Cambridge University Press.

Brown, D.M. (2010) Communicating Design: Developing Web Site Documentation for Design and Planning (2nd Edition), New Riders.

Bucciarelli, L.L. (1988) An Ethnographic Perspective on Engineering Design, Design Studies, Vol. 9, Issue 3, July 1998.

Carroll, J.M. (1995) Scenario-Based Design, Wiley.

Cecil, J. \& Kanchanapiboon, A. (2007) Virtual Engineering Approaches in Product and Process Design. The International Journal of Advanced Manufacturing Technology 31(9-10), 846-856.

Cheng, N.Y. (2003) Approaches to Design Collaboration Research. Automation in Construction, 12 (2003) 715- 723.

Churchill, E., \& Snowdon, D. (1998) Collaborative Virtual Environments: An Introductory Review of Issues and Systems, Virtual Reality 3(1), 3-15.

Cross N., Christiaans H., Dorst, K. (1997) Analysing Design Activity, Wiley.

Cross, N. and Cross, A.C. (1995) Observations of Teamwork and Social Processes in Design, Design Studies, Elsevier, 16 (1995) 145-170.

Cross, N. (2008). Engineering Design Methods: Strategies for Product Design (4th ed.). Wiley.

D’ Souza, N. Yooz, S.-Y. \& Islam, Z. (2011) Understanding Design Skills of the Generation Y: An Exploration through the VR-KiDS Project, Design Studies, 32 (2011) 180-209.

Dangelmaier, W. Fischer, M. Gausemeier, J. Grafe, M. Matysczok, C. \& Mueck, B. (2005). Virtual and Augmented Reality Support for Discrete Manufacturing System Simulation, Computers in Industry, Volume 56 Issue 4, May 2005. 
Drettakis, G. Roussou. M. Reche, A. Tsingos, N. (2007) Design and Evaluation of a Real-World Virtual Environment for Architecture and Urban Planning, Presence: Teleoperators and Virtual Environments 16, 3 (2007), 318-332.

Endsley, M. R. (1995) Measurement of Situation Awareness in Dynamic Systems. Human Factors, 1995 (37) 1, pp. 65-84.

Endsley, M.R. (1988). Situation awareness global assessment technique (SAGAT). Proceedings of the National Aerospace and Electronics Conference (NAECON), 789-795. New York: IEEE.

Fjeld, M., Lauche, K., Bichsel, Voorhorst, F., Krueger, H. \& Rauterberg, M. (2002) Physical and Virtual Tools: Activity Theory Applied to the Design of Groupware. CSCW, 153-180.

Fussell, S.R. Kraut, R.E. and Siegel, J. (2000) Coordination of Communication: Effects of Shared Visual Context on Collaborative Work, Proceedings of the 2000 ACM conference on Computer Supported Cooperative Work, pp. 21-30, New York, NY, USA.

Grudin, J. (1991) Obstacles to User Involvement in Software Product Development with Implications for CSCW, International Journal of Man-Machine Studies, 34, $3,435-452$.

Gul, L. F. and Maher, M. L. (2009) Co-Creating external design representations: comparing face-to-face sketching to designing in virtual environments, CoDesign International Journal of CoCreation in Design and the Arts, Vol 5(2):117-138.

Harrison, S., \& Dourish, P. (1996). Re-place-in space: The roles of place and space in collaborative systems. Proceedings of the 1996 ACM Conference on Computer Supported Cooperative Work, pp.67-76, New York, NY, USA.

Hmelo-Silver, C.E. (2004) Problem-Based Learning: What and How Do Students Learn? Educational Psychology Review, Vol. 16, Sep. 2004, pp. 235-266. 
John, B., \& Packer, H. (1995). Learning and Using the Cognitive Walkthrough Method: A Case Study Approach. Proceedings of the Conference on Human Factors in Computing Systems (SIGCHI 95) (pp. 429-436). Denver, Colorado.

Kan, H.Y., Duffy, V.G., \& Su C.-J. (2001). An Internet Virtual Reality Collaborative Environment for Effective Product Design, Computers in Industry 45(2), 197213.

Kan, J.W.T. Tsai, J.J.-H. Wang, X. (2011) "Scales” Affecting Design Communication in Collaborative Virtual Environments, in Wang \& Tsai (eds.) Collaborative Design in Virtual Environments, pp. 77-88, Springer.

Kim, M.J. \& Maher, M.L. (2008) The Impact of Tangible User Interfaces on Spatial Cognition During Collaborative Design, Design Studies, 29 (2008) 222-253.

Kohler, T., Matzler, K., \& Fuller, J. (2009) Avatar-based innovation: Using virtual worlds for real-world innovation, Technovation 29(6-7), 395-407.

LaViola Jr., J.J. (2000) A discussion of cybersickness in virtual environments, SIGCHI Bull. 32(1), 47-56.

Lahti, H. Seitamaa-Hakkarainen, P. Hakkarainen, K. (2004) Collaboration Patterns in Computer Supported Collaborative Designing, Design Studies, Vol. 25, No. 4, pp. 351-371, July 2004.

Madathil, K.C. \& Greenstein J.S. (2011) Synchronous Remote Usability Testing - A New Approach Facilitated By Virtual Worlds, in Proc. of CHI 2011, pp. 22252234, May 7-12, 2011, Vancouver, BC, Canada.

Maher, M.L. (2011) Designers and Collaborative Virtual Environments, in Xiangyu Wang and Jerry Jen-Hung Tsai (eds.) Collaborative Design in Virtual Environments, Chapter 1, pp. 3-15, Springer, 2011.

Maisch, B. \& Tobies, K. (2010) Innovation Communication in Virtual Worlds: A Multiple Case Study Analysis in Second Life, Innovation Journalism Vol 7(9).

Matthews, M. D., Pleban, R. J., Endsley, M. R., and Strater, L. G. (2000) Measures of Infantry Situation Awareness for a Virtual MOUT Environment. Proceedings of 
the Human Performance, Situation Awareness and Automation: User Centred Design for the New Millennium, Savannah, GA: SA Technologies, Inc.

Merrick, K.E., Gu, N., \& Wang, X. (2011). Case Studies Using Multiuser Virtual Worlds as an Innovative Platform for Collaborative Design, ITcon 16, 165-188.

Mobach, M.P. (2008) Do Virtual Worlds Create Better Real Worlds? Virtual Reality 12:163-179.

Nielsen, J., \& Molich, R. (1990). Heuristic evaluation of user interfaces. Proc. ACM CHI'90 Conference, Seattle, WA, 1-5 April, pp. 249-256.

Normand, V., Babski, C., Benford, S., Bullock, A., Carion, S. et al. (1999). The COVEN Project: Exploring Applicative, Technical, and Usage Dimensions of Collaborative Virtual Environments, Presence: Teleoper. Virtual Environ. 8(2), 218-236.

Pedgley, O. (2007) Capturing and Analysing Own Design Activity, Design Studies, Vol. 28 No. 5 September 2007.

Rekimoto J. (1996). Transvision: A Hand-held Augmented Reality System for Collaborative Design. In Proceedings of Virtual Systems and Multimedia '96 (VSMM '96).

Romiszowski, A. \& Mason, R. (1996). Computer-Mediated Communication. In D. Jonassen, ed., Handbook of Research for Educational Communications and Technology, pp. 438-456. New York: Macmillan.

Roussos, M., Johnson, A., Moher, T., Leigh, J., Vasilakis, C., \& Barnes, C. (1999) Learning and Building Together in an Immersive Virtual World. Presence: Teleoper. Virtual Environ. 8(3), 247-263.

Saco, R., Goncalves A., (2008), Service Design: An Appraisal, Design Management Review, Vol. 19, Issue 1.

Salmon, M. Stanton, N. Walker, G. Green, D. (2006) Situation Awareness Measurement: A Review of Applicability for C4i Environments. Applied Ergonomics, Vol. 37, Issue 2, pp.225-238 
Schmeil, A. Eppler, M.J. (2008) Knowledge Sharing and Collaborative Learning in Second Life: A Classification of Virtual 3D Group Interaction Scripts, Journal of Universal Computer Science, vol. 14, no. 3 (2008), 665-677.

Schmidt, K. and Bannon, L. (1992) Taking CSCW seriously, CSCW, Volume 1, Numbers 1-2, 7-40.

Schön, D. (1983) The Reflective Practitioner, Temple-Smith, London.

Sharp, H. Rogers, Y. \& Preece, J. (2007) Interaction Design - Beyond HumanComputer Interaction (2nd Edition) John Wiley \& Sons.

Snyder, C. (2003) Paper Prototyping. Morgan Kauffman.

Strauss, A. Corbin, J.M. (1990) Basics of qualitative research: Grounded theory procedures and techniques, Thousand Oaks, CA, US: Sage Publications, Inc.

Tullis T. and Albert, B. (2008) Measuring the User Experience, Morgan Kaufmann.

Valkenburg, R. and Dorst, K. (1998) The Reflective Practice of Design Teams, Design Studies 19 (1998) 249-271.

Vosinakis, S. Koutsabasis, P. Stavrakis, M, Viorres, N. Darzentas, J. (2008) Virtual Environments for Collaborative Design: Requirements and Guidelines from a Social Action Perspective, CoDesign: International Journal of CoCreation in Design and the Arts, Taylor and Francis, Volume 4 Issue 3, pp. 133-150, 2008.

Vosinakis, S. Koutsabasis, P. Zaharias, P. (2011a) An Exploratory Study of ProblemBased Learning in Virtual Worlds, Proc. 3rd International Convergence in Games and VWs for Serious Applications (VS-Games 2011), May 4-6 2011, Technical University of Athens (NTUA), Athens, Greece.

Vosinakis, S. Koutsabasis, P. Zaharias, P. Belk, M. (2011b) Problem-based Learning in VWs: a Case Study in User Interface Design, in Proc. 1st Global Conference: Experiential Learning in Virtual Worlds, March 20-22, Prague, Czech Republic.

Wood DF (2003) ABC of Learning and Teaching in Medicine: Problem Based Learning, British Medical Journal, 2003; 326: 328-30. 
